\title{
Quantifying Uptake and Retention of Copper Ions in Silica-Encrusted Chlamydomonas reinhardtii
}

Xiaohui Li ${ }^{1}$, Shanying Gui ${ }^{2}$, Mohammed Bhuiyan², Weiqiao Zeng ${ }^{2}$, Yagya Subedi², Rong Wang ${ }^{1}$ and Liaohai Chen ${ }^{2 *}$

${ }^{1}$ Department of Biological, Chemical and Physical Sciences, Illinois Institute of Technology, Chicago, IL 60616, USA

${ }^{2}$ Department of Chemistry and Biochemistry, Utah State University, Logan, UT 84322, USA

\begin{abstract}
Using copper (II) ion as a model pollutant, we report a new bioremediation concept, which involves the use of green algae Chlamydomonas reinhardtii to efficiently collect copper ions from the solution, followed by encapsulating copper loaded algae with silica, thus reducing the bioavailability of copper ions in the solution. Specifically, the potential of Chlamydomonas reinhardtii as an active copper (II) absorbent was demonstrated by quantifying and characterizing the copper uptake rate, capacity, efficacy, as well as copper retention from $C$. reinhardtii. Subsequently, a method of encrusting copper loaded C. reinhardtii with silica was developed, taking the advantage that the presences of high abundant polysaccharides and glycoproteins on the cell walls, as well as the presence of (3-amino-propyl) trimethoxysilane (APS) can function as nucleation center for silicification process of tetramethyl orthosilicate (TMOS). Both fluorescence imaging and scanning electron microscope (SEM) imaging confirmed the silica encrustation. It is expected that silica encrustation of algae has the potential for in situ remediation of various contaminants in a wide range of environments while providing long-term stabilization and diminishing the bioavailability of the contaminants.
\end{abstract}

Keywords: In vivo copper quantification; Chlamydomonas reinhardtii; Bioremediation; Silica encrustation

\section{Introduction}

Effective management of contaminated marine and freshwater is a challenging problem with far-reaching economic and ecological consequences. Current technologies for remediating contaminated environmental water include both ex situ and in situ remediation. In ex situ remediation, water is forced to pass through immobilized absorbents and the contents are extracted from water and immobilized in the absorbents. Ex situ remediation are expensive, as the need for large-scale water and absorption material handling. On the other hand, in situ remediation methods are less energy intensive and less expensive. Thus, it has the potential to remediate contaminated water in large scales.

In situ remediation applies absorbing materials such as activated charcoal or microbes to absorb contaminants [1-3]. Activated charcoal can strongly collect and concentrate various metal ions and organic compounds due to their porous structures. Yet, its unspecific absorbance leads to various organic and inorganic compounds competing for sorption sites, facilitating the release of contaminants to the environment. On the other hand, in situ bioremediation, using microbes to degrade or transform contaminants to less toxic and nontoxic forms, is being used to remediate certain contaminants, including heavy metal ions of uranium and cadmium, organic contaminants, such as polycyclic aromatic hydrocarbons (PAHs), organohalides, etc. [4,5]. However, the key drawbacks for in situ bioremediation are the limited availability of organisms to effectively metabolize/detoxify the contaminants as well as slow remediation rate due to the combination of respiratory and co-metabolic processes. Our research aims at tackling these challenges by exploring a new approach of not only efficiently absorbing contaminants, but also encrusting the absorbed contaminants to reduce their bioavailability in the aqueous environment.

Many algae/microbe species are capable of aggressively uptaking and accumulating various contaminants, including organic compounds, metal ions, and metalloids [6-9]. However, the use of marine and freshwater algae for conventional in situ bioremediation is limited because of the ineffective metabolism/detoxification process. We proposed a bold approach to develop a new remediation method by sealing the pregnant algae, thus dramatically reducing the bioavailability of the contaminants to the environment, instead of replying on alga's metabolic detoxification process. The use of living algae as sorbents for both organic and metal (especially free metal ion and metalloid [8] contaminants could address complex contaminant mixtures in contaminated waters. More importantly, it is environment friendly. In this study, we used a well studied Chlamydomonas reinhardtii (C. reinhardtii) as a model microbe to demonstrate the proof-of-concept.

As one of the major biomineralization processes in nature, silicon mineralization is a widespread biological phenomenon observed in a large number of organisms. Silicon (Si), the second most abundant element on Earth, represents about one-fourth of the Earth's crust mass in the form of silicon dioxide (or silica) and various silicates. Biospecies face a high concentration of free $\mathrm{Si}$ as silicic acid $(70 \mu \mathrm{M}$ in the oceans on average, and $\sim 5 \mu \mathrm{M}$ in surface waters) [10]. The interaction between algae cell wall and silicic acid in the environment leads to precipitation of minerals and formation of silica crust over living organisms, such as diatoms. The nucleation process occurs directly on the cell wall, resulting in biominerals firmly attaching to and encrusting the cells. The gravitation of encrustation and subsequent mineral growth can overcome buoyancy. Eventually mineral "rocks" of the encrusted cells are settled in water. In this paper, we reported such a new remediation process of using alga to actively uptake and collect metal copper ions, followed by the addition of silicification enhancer molecules and silicic

*Corresponding author: Dr. Liaohai Chen, Department of Chemistry and Biochemistry, Utah State University, Logan, UT, 84322, USA, Tel: (435) 797-8626 E-mail: I.chen@usu.edu

Received: October 30, 2015; Accepted: November 26, 2015; Published November 30, 2015

Citation: Li X, Gui S, Bhuiyan M, Zeng W, Subedi Y, et al. (2015) Quantifying Uptake and Retention of Copper lons in Silica-Encrusted Chlamydomonas reinhardtii. Biochem Anal Biochem 4: 228. doi:10.4172/2161-1009.1000228

Copyright: (C) $2015 \mathrm{Li} \mathrm{X}$, et al. This is an open-access article distributed under the terms of the Creative Commons Attribution License, which permits unrestricted use, distribution, and reproduction in any medium, provided the original author and source are credited. 
acids to encrust copper-loaded algae. The "mineralized" copper-loaded algae can consequently form large insoluble silica "rocks" and settle in the water, thus leading to the reduction of bioavailability of copper ions in water

\section{Material and Methods}

\section{Material}

C. reinhardtii 1 wild type (ATCC- $18798^{\mathrm{TM}}$ ) is used throughout the experiments. Copper (II) sulfate is used as copper source for all experiments. Hydroxylamine-hydrochloride $(99.999 \%$ $\left.\mathrm{NH}_{2} \mathrm{OH} \cdot \mathrm{HCl}\right)$, copper (II) sulfate pentahydrate $\left(\mathrm{CuSO}_{4} \cdot 5 \mathrm{H}_{2} \mathrm{O}\right)$, disodium bathocuproine disulfonate (2,9-dimethyl-4,7-diphenyl1,10-phenanthrolinedisulfonic acid disodium salt, $\mathrm{C}_{12} \mathrm{H}_{4} \mathrm{~N}_{2}$ $\left.\left(\mathrm{CH}_{3}\right)_{2}\left(\mathrm{C}_{6} \mathrm{H}_{4}\right)_{2}\left(\mathrm{SO}_{3} \mathrm{Na}\right)_{2}\right), 2$-(N-morpholino)-ethanesulfonic acid (MES, $\mathrm{pKa}=6.1$ ), Sodium dodecyl sulfate (SDS), Tetramethyl orthosilicate ( $\geq 99 \%$, TMOS), (3-amino-propyl) trimethoxysilane (90\%, APS), and fluorescein isothiocyanate isomer 1 (F7250) were purchased from Sigma-Aldrich and used as received.

Hewlett-Packard 8453 UV-Vis spectrophotometer was used for absorbance determination. Olympus IX70 fluorescence microscope was used for fluorescence imaging. High resolution FEI thermal field emission scanning electron microscope (SEM)-Nova NanoSEM 200 was used for SEM imaging.

\section{Culturing C. reinhardtii}

C. reinhardtii cells were grown in the modified Gorman and Levine (1965) TAP medium [11] adjusted to $\mathrm{pH} 7.2$, and maintained in Erlenmeyer flasks with a 14:10 hr light-dark cycle using cool-white fluorescent light and a shake speed of $110 \mathrm{rpm}$ at room temperature. All glassware used for culturing and testing was sterilized before using. The density of $C$. reinhardtii cells was determined by the optical density measurement of cell density at $550 \mathrm{~nm}$. The cell suspension was diluted into the linear response region (absorbance $<1.5 \mathrm{OD}$ ), and the cell density for 1.0 OD was $5 \times 10^{6}$ cells $/ \mathrm{mL}$.

\section{Measurement of the copper (II) ion concentration}

The copper (II) ion concentration in aqueous solution was measured according to the modified APHA standards 2005 [12]. Typically, in a $10 \mathrm{~mL}$ tube, $0.2 \mathrm{~mL}$ of $0.11 \mathrm{~g} / \mathrm{L}$ hydroxylamine-hydrochiloride solution and $0.2 \mathrm{~mL}$ of $0.01 \mathrm{~g} / \mathrm{L}$ disodium bathocuproine disulfonate solution were added into $2.0 \mathrm{~mL}$ of MES buffer $(0.2 \mathrm{~mol} / \mathrm{L}, \mathrm{pH}=6.5)$. The absorbance was measured at $484 \mathrm{~nm}$. All the samples tested were diluted to the linear response region of $0.02-4 \mathrm{ppm}$ of copper (II) ion concentration. Since copper ion tends to be adsorbed on the surface of sample containers, samples were analyzed as soon as possible after collection.

\section{Visualization of copper uptake using x-ray-fluorescence}

$\mathrm{X}$-ray optics at third-generation synchrotron sources is capable of visualizing and measuring intracellular metals in biological samples with a high sensitivity. In brief, $C$. reinhardtii cells were incubated with $5 \mu \mathrm{M}$ copper $\left(\mathrm{CuSO}_{4} .5 \mathrm{H}_{2} \mathrm{O}\right)$ at room temperature. After 5,30 , and 60 min, the cells were washed with $100 \mu \mathrm{M}$ EDTA to remove any copper ions that were outside the cells. Copper-loaded cells were then fixed by glutaraldehyde and mounted on silicon nitride windows. Another algae sample without exposed to copper solution was also prepared as an endogenous copper control sample. All the samples were plunge frozen and X-ray fluorescence imaging was conducted in beamline 2-ID-E at the Advanced Photon Source (Argonne, IL).

\section{Characterization of the copper (II) uptake and release process for $C$. reinhardtii}

The copper (II) uptake tests were accomplished in the following manner. The pre-cultured algal cells in the middle of the logarithmic phase were collected by centrifugation at $600 \times \mathrm{g}$ for $6 \mathrm{~min}$, and washed thoroughly with the uptake solution and then resuspended in a 250 ml Erlenmeyer flask with $25 \mathrm{~mL}$ solution containing copper (II), and then the cells were incubated under the regular cell culturing condition. After the desired incubation period $(0,15,30,60,120$, and $180 \mathrm{~min})$, the aqueous solution were separated from the algae by centrifugation at $600 \times \mathrm{g}$ for $6 \mathrm{~min}$, and the concentration of copper (II) ion in the supernatant was measured by the colorimetric method described above. The uptake cell density was determined by measuring the optical density at $550 \mathrm{~nm}$. The uptake process was monitored for 3 hours unless specified.

The amount of copper (II) ions taken up per C. reinhardtii cell, $q$ ( $\mu \mathrm{g}$ copper /cell), was obtained by using the following expression:

$$
q=\left[\left(C_{0}-C\right) \cdot V_{\text {cu }}\right] /\left(d \cdot V_{\text {cell }}\right) \approx\left(C_{0}-C\right) / d
$$

where $C_{0}$ and $C$ are the concentrations of the heavy metal in the initial solution and after uptake, respectively $(\mu \mathrm{g} / \mathrm{mL}, \mathrm{ppm}) ; V_{\mathrm{cu}}$ is the volume of the cell contained copper (II) solution $(\mathrm{mL}) ; V_{\text {cell }}$ is the volume of the copper (II) cell suspension (mL) and $d$ is the density of C. reinhardtii cell (cell/mL). Since the sample for $\mathrm{Cu}^{2+}$ concentration measurement was from the same solution as samples for the cell density measurement, the value of $V_{\mathrm{cu}}$ is approximately equal to that of $V_{\text {cell }}$. Thus, copper (II) ion is independent of the volume change of the uptake solution. Each experiment was repeated three times and the results given were the average values with error bars indicating the standard deviation.

For the copper (II) release process, the algal cells incubated in the copper (II) solutions for 3 hours were collected by centrifugation at 600 $\times \mathrm{g}$ for $6 \mathrm{~min}$, and washed thoroughly with water or release solutions and then resuspended with $25 \mathrm{~mL}$ of water or release solutions without copper (II) ions. After the desired incubation period (0, 15, 30, 60, 120, and $180 \mathrm{~min}$ ), the concentration of copper (II) ion and the cell density in this supernatant were measured as stated above. The release test was carried out in sterilized deionized $\mathrm{H}_{2} \mathrm{O}$ and the MES buffer $(0.2 \mathrm{M}, \mathrm{pH}$ 6.5), respectively. Different chemical treatments for copper (II) release conditions included: 1) washing the cells with different buffer solution, 2) heating the cells up to $75^{\circ} \mathrm{C}$ for 1 hours, and 3) treating the cells with chemicals such as $1 \%$ SDS for 1 hour, and $70 \% \mathrm{HNO}_{3}$ for 3 hours.

\section{Encapsulation of algal cells with silica shells}

The FITC-silanes were prepared by mixing $0.265 \mathrm{ml}$ of APS and 5 $\mu \mathrm{mol}$ of fluorescein isothiocyanate (FITC) diluted in $5 \mathrm{ml}$ anhydrous ethanol as a co-solvent [13]. The reaction mixture was stirred at ambient temperature for 3 hours. Water is excluded to prevent hydrolysis and condensation of APS molecules. And storage and synthesis with FITC are performed in the dark to avoid bleaching [14].

Silicic acid solution was freshly prepared by hydrolyzing $1 \mathrm{M}$ TMOS in $1 \mathrm{mM} \mathrm{HCl}$ for $15 \mathrm{~min}$ at room temperature. The algal cells were suspended in $1 \mathrm{~mL}$ of phosphate buffer saline (PBS), followed by addition of $30 \mu \mathrm{L}$ of pre-hydrolyzed TMOS for $\mathrm{SiO}_{2}$ shell formation [15]. $2 \mu \mathrm{L}$ of APS was added to catalyze/initialize silica polymerization, and the sample was incubated for $5 \mathrm{~min}$ at ambient temperatures. Samples were washed 3 times with PBS buffer to remove free silicic acid, then resuspended in $1 \mathrm{~mL}$ PBS buffer followed by adding $10 \mu \mathrm{L}$ of APS-FITC to coat the silica surface. Samples were washed 3 times 
with PBS buffer to remove free APS-FITC, and the washed pellets were resuspended in $0.5 \mathrm{~mL}$ of PBS buffer for direct visualization of silica shells on algae surface.

\section{Image acquisition and processing}

Fluorescence images were obtained using an Olympus IX70 Microscope. Transmitted illumination was provided by a tungstenhalogen lamphouse, and fluorescence illumination was provided by a mercury lamphouse. SEM images were obtained by firstly preparing the sample of silica encapsulated algal cells through fixation and dehydration steps. Algae samples were fixed with formaldehyde (final concentration 2.5\%) for 2 hours at room temperature and then washed 3 times with distilled water, followed by washing with ethanol series of $50 \%, 70 \%, 80 \%, 90 \%, 95 \%$, and $100 \%$. Finally, the samples were coated with gold and analyzed on Nova NanoSEM 200.

\section{Results}

\section{Copper (II) uptake by C. reinhardtii}

We first examined how different concentrations of $\mathrm{Cu}^{2+}$ ions could influence the growth of $C$. reinhardtii by monitoring the algae growth rate as a function of copper concentrations (data showed in Supplementary Materials). It was found that $\mathrm{Cu}^{2+}$ ion in the concentration range from 0 to $7.6 \mathrm{ppm}$ is not likely to affect the growth of $C$. reinhardtii while significant inhibition appeared around $14.2 \mathrm{ppm}$ of copper (II). At $56.9 \mathrm{ppm}$ of copper (II), the algal growth was considerably prohibited (Figure S1). Accordingly, uptake studies were carried out using three different $\mathrm{Cu}^{2+}$ concentrations of $1.62 \mathrm{ppm}$ (no influence), $15.6 \mathrm{ppm}$ (inhibition influence), and $49.6 \mathrm{ppm}$ (toxic influence) to evaluate the uptake efficiencies of $C$. reinhardtii against $\mathrm{Cu}^{2+}$ ions.

After incubating C. reinhardtii in copper (II) solutions, both concentrations of copper (II) that remained in the solution and the copper (II) concentration accumulated in the algae cells were measured
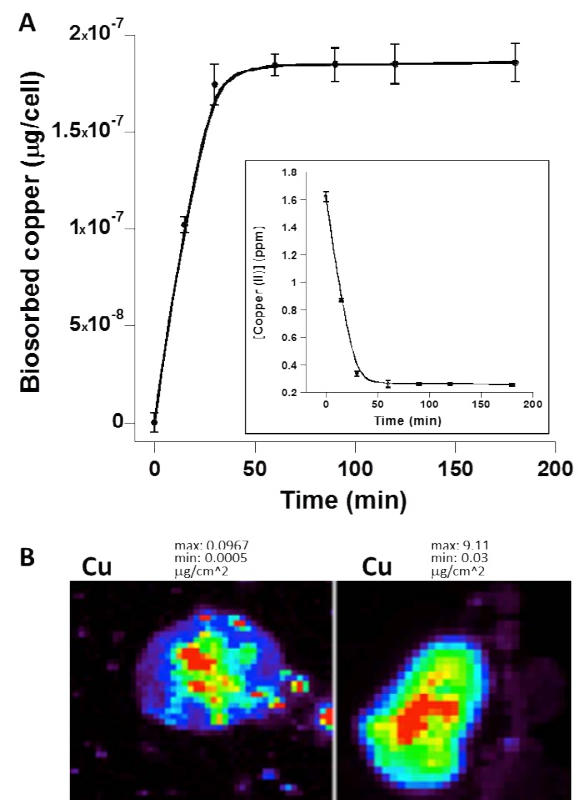

Figure 1: Uptake of Copper (II) on C. reinhardtii. (A) Concentrations of Cu (II) within the $\mathrm{C}$. reinhardtii cells during uptake with the original $\mathrm{Cu}$ (II) concentration of $1.62 \mathrm{ppm}$. The insert graph illustrates the concentrations of $\mathrm{Cu}$ (II) in solution during the algae uptake process. (B) X-ray fluorescence images of $C$. reinhardti cells with endogenous copper (left) and uptaken copper (right).
A

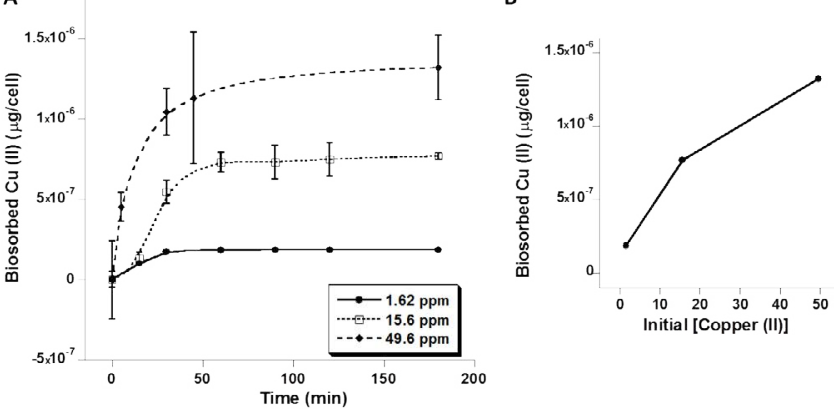

Figure 2: (A) Effect of the initial concentrations of $\mathrm{Cu}$ (II) on the uptake rates by $C$. reinhardtii. (B) The uptake capacity of algae as a function of the original concentration of $\mathrm{Cu}$ (II) ions.

using a Bathocuproine Method. When the $\mathrm{Cu}^{2+}$ concentration was $1.62 \mathrm{ppm}$, the copper (II) absorbed by C. reinhardtii rapidly increased during the first $30 \mathrm{~min}$ and then plateaued gradually within $60 \mathrm{~min}$ (Figure 1A). The copper (II) concentration in solution was reduced to $0.25 \mathrm{ppm}$, indicating that $84 \%$ of copper (II) ions were removed from the solution by C. reinhardtii cells (remediation efficiency, Figure 1A inset).

The amount of copper (II) absorbed within each cell was calculated based on Equation [1] with a cell density of approximately $7.3 \times 106$ cell $/ \mathrm{mL}$. The amount of copper (II) absorbed by each cell increased significantly from an undetectable level to $1.86 \times 10-7 \mu \mathrm{g} / \mathrm{cell}$ (about $1.76 \times 109$ copper (II) ion/cell) during the uptake period. After this uptake period, the amount of biosorbed copper (II) ions on $C$. reinhardtii did not change significantly over time.

Copper ion uptake was also visualized directly by using synchrotron $\mathrm{x}$-ray fluorescence. Recent developments in $\mathrm{x}$-ray optics in third-generation synchrotron sources enable highly sensitive visualization and quantification of intracellular metals in biological samples. Accordingly, we applied $\mathrm{x}$-ray fluorescence microscopy (XRF) to visualize and compare both endogenous cellular copper and endocytosed copper in algae. As shown in Figure 1B, algae cells exhibited maximum endogenous copper density of $0.0967 \mu \mathrm{g} / \mathrm{cm}^{2}$ (Figure 1B, left). However, copper loaded cells had maximum copper density of $9.11 \mu \mathrm{g} / \mathrm{cm}^{2}$ (Figure 1B, right) -100 times greater than the endogenous value. Since the cells were incubated and washed with EDTA solution multiple times, nonspecific absorption of copper ions on the surface of algae cells had been removed. Thus, the resulting XRF images illustrated the endocytosed coppers within the cells.

Uptake efficiencies were further studied at the copper concentrations of $1.62,15.6$, and $49.6 \mathrm{ppm}$ in deionized $\mathrm{H}_{2} \mathrm{O}$. As shown in Figure 2A, the threshold of copper (II) uptake occurred after 30 minutes, regardless of the concentration difference. With a higher initial $\mathrm{Cu}^{2+}$ concentration, more $\mathrm{Cu}^{2+}$ ions were absorbed by each algal cell (Table 1), indicating an increased uptake capacity (Figure $2 \mathrm{~B}$ ). However, with a higher $\mathrm{Cu}^{2+}$ concentration, the remediation efficiency decreased (Table 1), which was possibly due to the uptake capacity gradually saturated when the copper (II) concentration continually increased. The results suggested that $C$. reinhardtii cells have the ability to uptake large amount of copper (II) ions from aqueous systems, and the remediation efficiency displays a copper (II) concentration dependence.

\section{Copper release from copper-loaded C. reinhardtii}

To evaluate the retention of copper ions in copper-loaded $C$. 
reinhardtii, we quantified the release of copper (II) associated with $C$. reinhardtii. Briefly, after isolating copper-loaded algae, the cells were incubated in pure water. The changes of $\mathrm{Cu}^{2+}$ concentrations in water were monitored, and the percentage of $\mathrm{Cu}^{2+}$ released to water was calculated. As shown in Figure 3A, within three-hour incubation, the $\mathrm{Cu}^{2+}$ concentration in solution remained lower than $0.1 \mathrm{ppm}$, and the amount of absorbed $\mathrm{Cu}^{2+}$ ions on C. reinhardtii did not change significantly with time. The release percentages under different original copper concentrations were calculated and listed in Table 2. Less than

\begin{tabular}{|c|c|c|c|c|}
\hline $\begin{array}{c}\text { Initial }\left[\mathbf{C u}^{2+}\right] \\
(\mathbf{p p m})\end{array}$ & $\begin{array}{c}{\left[\mathrm{Cu}^{2+}\right] \text { After }} \\
\text { Uptake (ppm) }\end{array}$ & $\begin{array}{c}\text { Cu}{ }^{2+} \text { Removal } \\
\text { Efficiency }\end{array}$ & $\begin{array}{c}\text { Cell Density } \\
(\mathbf{c e l l} / \mathbf{m L})\end{array}$ & $\begin{array}{c}\text { Uptake Capacity } \\
\text { (copper/cell) }\end{array}$ \\
\hline 1.62 & 0.25 & $84.5 \%$ & $7.4 \times 10^{6}$ & $1.8 \times 10^{9}$ \\
\hline 15.6 & 12.4 & $20.8 \%$ & $4.3 \times 10^{6}$ & $7.3 \times 10^{9}$ \\
\hline 49.6 & 42.2 & $14.8 \%$ & $5.9 \times 10^{6}$ & $1.2 \times 10^{10}$ \\
\hline
\end{tabular}

Table 1: Effect of the initial concentration of Copper (II) on the uptake rates.
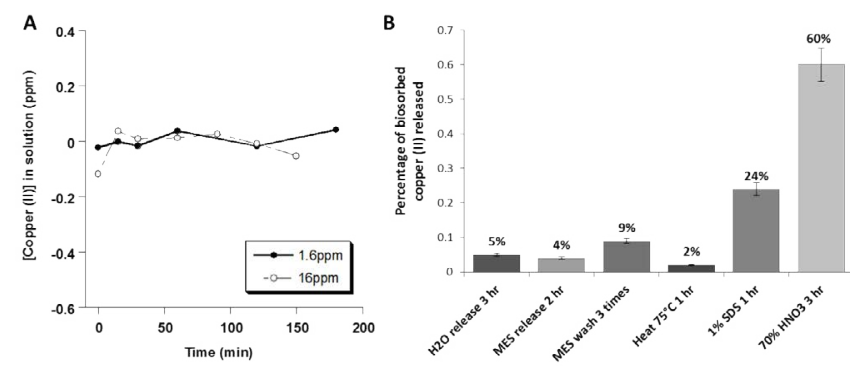

Figure 3: Characterization of the Copper (II) release process with different original $\mathrm{Cu}^{2+}$ concentrations $(\mathrm{A})$ and different release conditions $(\mathrm{B})$.

\begin{tabular}{|c|c|c|c|c|}
\hline $\begin{array}{c}\text { Initial }\left[\mathbf{C u}^{2+}\right] \\
(\mathbf{p p m})\end{array}$ & $\begin{array}{c}\mathbf{C C u}^{2+} \text { after } \\
\text { Uptake (ppm) }\end{array}$ & $\begin{array}{c}\mathbf{C u}^{2+} \text { Taken-Up } \\
\text { (mg) }\end{array}$ & $\begin{array}{c}\mathbf{C u}^{2+} \text { Released } \\
\text { (mg) }\end{array}$ & $\begin{array}{c}\text { Release } \\
\text { Percentage }\end{array}$ \\
\hline 1.62 & 0.25 & 34.2 & 1.6 & $4.69 \%$ \\
\hline 15.64 & 12.38 & 81.4 & 3.9 & $4.74 \%$ \\
\hline
\end{tabular}

Table 2: Percentage of Copper (II) released in water.

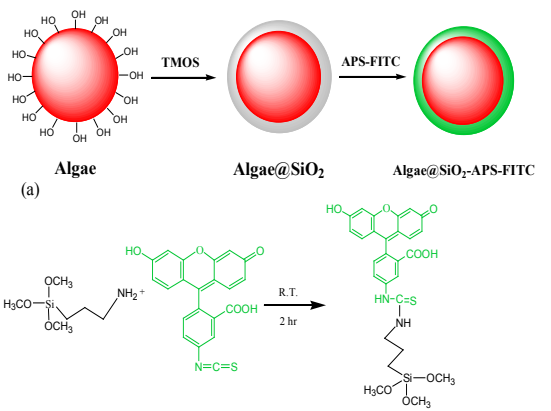

(b)

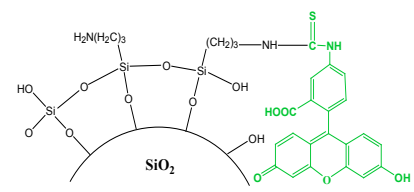

Figure 4: (a) Schematic illustration of silica encapsulation outside algal cells. (b) Chemical reaction of labeling APS with FITC. (c). Schematic representation of the silica crust surface coated with FITC-APS.
$5 \%$ of $\mathrm{Cu}^{2+}$ was released from C. reinhardtii at copper concentrations of 1.62 and $15.64 \mathrm{ppm}$, indicating strong binding between copper (II) and cell components of $C$. reinhardtii.

Furthermore, we studied the $\mathrm{Cu}^{2+}$ release from copper-loaded $C$. reinhardtii under the influence of chemical treatments. As shown in Figure $3 \mathrm{~B}$, less than $5 \%$ of copper (II) was released when copper-loaded cells were incubated with MES buffer containing 10\% of EDTA. Only $9 \%$ of $\mathrm{Cu}^{2+}$ ions were released when the copper-loaded algal cells were washed 3 times with the MES buffer containing 10\% of EDTA. Even when the solution of copper-loaded algal cells was heated for 2 hours, the amount of copper (II) released was negligible. This suggests that most of absorbed copper (II) ions are stably associated with algal cells either through cell wall conjugations or intracellular interactions.

When using much harsher conditions like SDS (to dissociate the algal cell) or concentrated $\mathrm{HNO}_{3}$ (to digest cells) treatment, significantly higher amounts of copper (II) were released into solution ( $24 \%$ and $60 \%$, respectively), as shown in Figure 3B. Theoretically, $\mathrm{HNO}_{3}$ digestion could completely lyse algae cells and release $100 \%$ of the intracellular copper ions. However, the strong acidic condition could dramatically influence the absorbance of copper-bathocuproine complex in measurement; thus, $60 \%$ of releasing efficiency calculated for the $\mathrm{HNO}_{3}$ treatment may not reflect a true number. Nevertheless, these results suggested that $C$. reinhardtii is an excellent absorbent with great stability under mild conditions.

\section{Silica encapsulation of copper loaded Chlamydomonas rein- hardtii}

To use algae as a bioremediation platform, the bioavailability of copper ions associated with copper-loaded C. reinhardtii needs to be reduced significantly in water. This was achieved by encrusting algae through biomineralization. The formation of inorganic crust over a living organism is a widespread biological phenomenon, and one of the major biomineralization processes is the deposition of silica in biologic systems. The chemical structure of cell wall of $C$. reinhardtii, which contains high abundance of hydroxyl $(-\mathrm{OH})$ groups on the sugar/ hydroproline units and amino $\left(-\mathrm{NH}_{2}\right)$ and carboxyl $(-\mathrm{COOH})$ groups on the protein, can be advantage for silica deposition. We hypothesized that the cell walls of algae can serve as causal agents for nucleation of silica, polymerization of silicic acid, and adhesion to other silica materials for subsequent silica encapsulation, as shown in Figure 4A.

In brief, copper loaded algae cells were treated with APS and TMOS for silica condensation on the cell surface. To observe the silica encrustation under microscope, we also coated the algal cells with the fluorescent-labeled silane (APS-FITC) outside the $\mathrm{SiO}_{2}$ layer (Figure 4B and $4 \mathrm{C}$ ). After silica encapsulation, the size and shape of $C$. reinhardtii cells (algae@SiO ) remained similar (Figure 5a-5c). Due to the broad absorbance of the visible light region in C. reinhardtii, both fluorescence of APS-FITC and autofluorescence of algae can be observed when excited at $480 \mathrm{~nm}$ (Figure $5 \mathrm{~d}$ and $5 \mathrm{~g}$ ). We also chose $535 \mathrm{~nm}$ as a control excitation wavelength, where APS-FITC shows no fluorescence (Figure 5d-5f). To demonstrate the green fluorescence from the silicified shell, we incubated the same amount of algae and algae@SiO, with the same amount of APS-FITC. The control group of algae treated with APSFITC only showed only weak fluorescence (Figure $5 \mathrm{~h}$ ) indicating that APS-FITC does not interact strongly with algal cells. On the other hand, most of the algae@SiO ${ }_{2}$ cells exhibit strong fluorescence (Figure 5i) in a ring structure on their surface, indicating the presence of a shell structure after silica encapsulation.

The structure of encapsulated algae cells were further examined 
Citation: Li X, Gui S, Bhuiyan M, Zeng W, Subedi Y, et al. (2015) Quantifying Uptake and Retention of Copper lons in Silica-Encrusted Chlamydomonas reinhardtii. Biochem Anal Biochem 4: 228. doi:10.4172/2161-1009.1000228

using scanning electron microscope (SEM). As shown in Figure 6, although algae@SiO maintained its original shape, the surface became rougher after biomimetic silicification (Figure 6a and $6 \mathrm{~b}$ ) compared to the uncoated algae cells (Figure 6c). Moreover, the surface of algae@ $\mathrm{SiO}_{2}$ is composed of silica nanoparticles (Figure 6d). The SEM images confirmed the encapsulation of algal cells within silica shells.

We further discovered that APS could function as an anchor molecule for silane condensation on the algal cell wall, thus enhancing the silica encapsulation process. Without APS added to the silane precursor (TMOS), the formed $\mathrm{SiO}_{2}$ did not nucleate on the cell surface (Figure 7a and 7c); instead, it self-nucleated in solution and condensed into irregularly shaped aggregates, leaving the cells uncovered with silica. In contrast, when APS was added to TMOS, it led to the nucleation of $\mathrm{SiO}_{2}$ around the algal cells and formed a silica shell to encapsulate algal cells (Figure $7 \mathrm{~b}$ and $7 \mathrm{~d}$ ). Thus, APS facilitates the formation of silica crust around algal cells.

\section{Silica encapsulation assisting copper removal from algae}

We further tested whether silicification facilitates the copper (II) bioremediation. We quantified and compared the copper

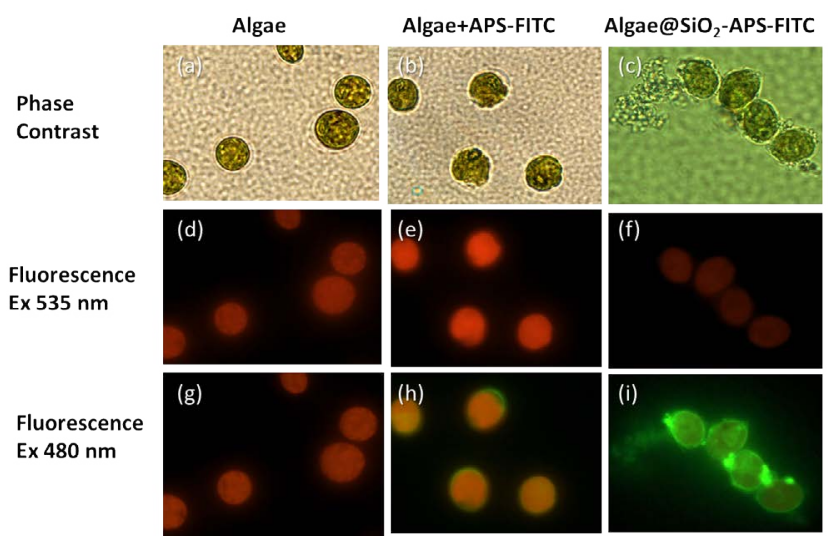

Figure 5: Microscopic images of silica encapsulation of C. reinhardtii. Algal cells, algal cells+APS-FITC, and algal cells@SiO - -APS-FITC: a-c, bright field images; d-f, fluorescence images using $535 \mathrm{~nm}$ excitation wavelength; and g-i fluorescence images using $480 \mathrm{~nm}$ excitation wavelength.

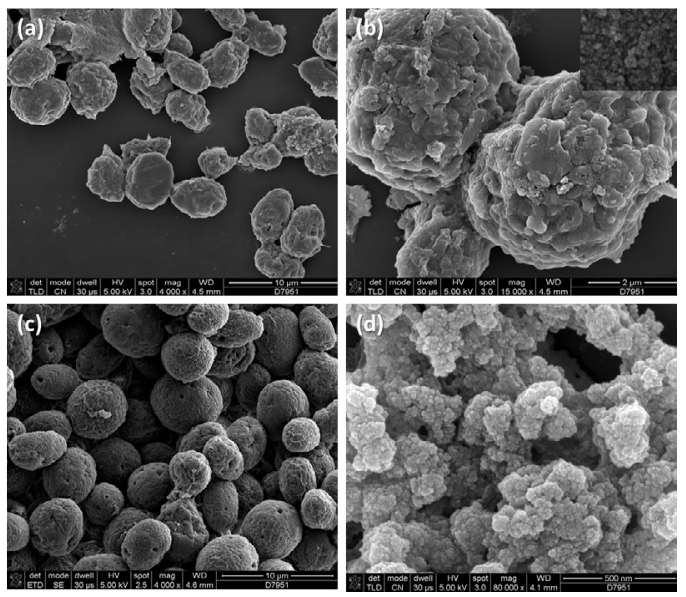

Figure 6: Surface characteristics of algae@ $\mathrm{SiO}_{2}$ at different magnifications $(\mathbf{a}, \mathbf{b})$, free algae (c), and silica nanoparticles alone (d). The scale bars are 10 $\mu \mathrm{m}$ (a) and (c), $2 \mu \mathrm{m}$ (b), and $500 \mathrm{~nm}$ (d). Inset figure in (b) shows the silica nanoparticles on the cell surface.

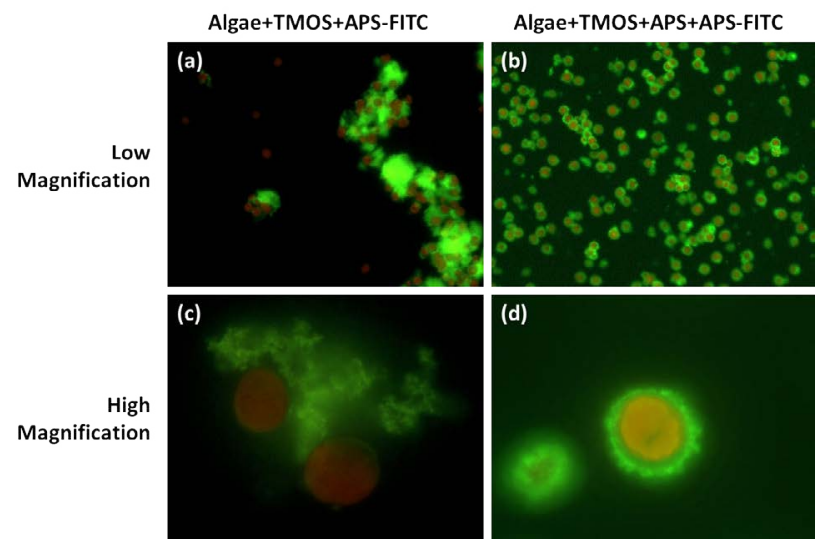

Figure 7: APS facilitates the silica encapsulation process. Low (a-b) and high (c-d) magnification fluorescence images excited at $480 \mathrm{~nm}$ of algal cell encapsulation without addition of APS after TMOS $(\mathbf{a}, \mathbf{c})$, and algal cell encapsulation with addition of APS after TMOS $(\mathbf{b}, \mathbf{d})$

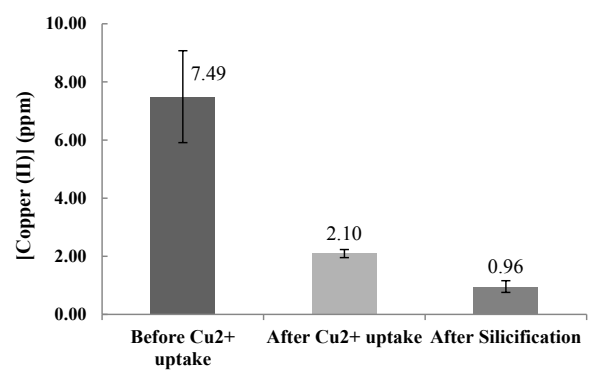

Figure 8: Efficiency of copper (II) removal by the algae@ $\mathrm{SiO}_{2}$ system before and after algae treatment and silica encapsulation.

concentrations in solution before and after $C$. reinhardtii treatment as well as after silicification process. With an original $\mathrm{Cu}^{2+}$ concentration of $7.5 \mathrm{ppm}, 2.1 \mathrm{ppm}$ copper (II) remained in solution after incubation with algal cells (Figure 8). Furthermore, the amount of copper (II) that remained in solution was reduced to less than $1.0 \mathrm{ppm}$ after silica encapsulation (Figure 8). This indicates that the silica condensation process could further trap copper ions within the silica shells. Overall, the combination of algae treatment and silicification process has the capability to remove $70 \%-80 \%$ of the copper (II) ions from water within 3 hours.

\section{Discussions}

Since $C$. reinhardtii can absorb an array of trace metals, including cobalt, nickel, lead, cadmium, and mercury [16-20], it is not surprising that we observed great copper uptake capability of $C$. reinhardtii. Although the growth of $C$. reinhardtii cells is sensitive to copper (Figure S1) [21-23], they exhibit an exceptional capacity for copper uptake (more than 109 copper ions per cell), and they can remove more than $80 \%$ of copper (II) in solution at a low copper (II) concentration (Table 1). At a high copper (II) concentration (49.6 ppm), the amount of copper (II) up-taken by $C$. reinhardtii increased by an order of magnitude, although with a lower remediation efficiency $(\sim 15 \%$, Table 1$)$. The low remediation efficiency probably resulted from the saturated absorbance of $C$. reinhardtii as well as the impaired growth of $C$. reinhardtii under such a high copper (II) concentration. Moreover, C. reinhardtii showed a remarkably low release percentage of the absorbed copper ions, unless treated with harsh chemical conditions, such as incubation with SDS or $\mathrm{HNO}_{3}$ (Figure 3). These results make C. reinhardtii a great choice for bioremediation. 
To reduce the bioavailability of the absorbed copper (II) in algae, we performed biomimetic silicification under mild conditions (room temperature, normal pressure, and neutral $\mathrm{pH}$ ) to encapsulate and encrust the algal cells with silica. Algal cells were successfully encapsulated with silica shells when APS was used. A plausible explanation for the function of APS is that, as a cation in neutral $\mathrm{pH}$, it could create an anchor point for silane condensation between the hydrolyzed silane anions [24] and the negatively charged carboxyl and hydroxyl groups on the cell surface. At the same time, APS could provide a basic environment for the silicification process and be a good catalyst for the silica encapsulation by offering silicic acid a template for further crosslink. On the other hand, while other organo-alkoxysilanes rapidly condensate to insoluble precipitates, APS remains stable in solution because hydrolyzed APS forms a six- or five- membered chelate ring and sterically hinders condensation [14]. Thus, APS probably acts as a template and catalyst for the silicification process around the cells. With APS added, algal cells were encapsulated with silica shells, so that the algae could be easily removed from the environment due to the "precipitation". Moreover, copper ions were further removed during silica encapsulation process (Figure 8). Because of the dense deposition of silica over the contaminant-loaded cells, we anticipate little, perhaps no bioavailability of contaminants, which prohibits the heavy metal contamination from re-entering the food chain.

Overall, the potential bioremediation method descried herein is different from "physical" remediation methods such as extraction or filtration, where infrastructure (filtration stations) and (electric) energy need to be involved. It is also different from the conventional bioremediation methods, which rely on the metabolism of microbes to remediation the contaminants. For algae, although they can very aggressively uptake/absorb metal and other contaminants, they lack the capability to convert/metabolize these contaminants. Thus contaminant-impregnated algae need to be separated/removed from water to reduce the contaminant's bioavailability. While a filtration method could be used, it will be difficult, considering the size of algae unless they can be selectively bound to larger particles (such as charcoal). Precipitation of contaminant-impregnated algae via natural biomineralization/biosilicification processes offers a simple, economic and natural way to reduce the bioavailability of contaminants. Silicic acid is a "natural product" (70 $\mu \mathrm{M}$ in the oceans on average), a minimal environment impact by using silicic acid for sedimentation is expected. Given the fact that algae are very robust microbes that can live in hot, toxic metal-rich, acidic environments [25], and biomineralization/ biosilicification happen in both fresh and marine water, we anticipate the proposed approach has the potential to be extended to remediate real contaminated marine and freshwater.

We demonstrated that the copper level in a water samples can be reduced to less than $1 \mathrm{ppm}$ from an initial concentration of $\sim 50 \mathrm{ppm}$ via alga treatment and silica-encrustation process. Considering the fact that typical copper concentrations in moderately polluted water/ sediment are in the range of 25-50 ppm, while sediments with copper concentrations less than $25 \mathrm{ppm}$ are considered as non-polluted [26], the proposed bioremediation method has a potential capacity to deal with real contaminated samples.

In summary, by using C. reinhardtii to treat a metal ion solution, followed by silicification around the cells, we are able to remove $70 \%$ $80 \%$ of the copper (II) ions from water within 3 hours. As a new strategy for bioremediation, which is still in an early, conceptual develop stage, additional studies need to be conducted with other pollutants to remediate pollution in different water systems.

\section{Acknowledgement}

We thank Dr. Lydia Finlay at Argonne National Laboratory for the help with $x$-ray fluorescence imaging.

\section{References}

1. Rakowska MI, Kupryianchyk D, Harmsen J, Grotenhuis T, Koelmans AA (2012) In situ remediation of contaminated sediments using carbonaceous materials. Environ Toxicol Chem 31: 693-704.

2. Cornelissen G, Krusa M E, Breedveld GD, Eek E, Oen AMP, et al. (2011) Remediation of Contaminated Marine Sediment Using Thin-Layer Capping with Activated Carbon-A Field Experiment in Trondheim Harbor, Norway. Environ Sci Technol 45: 6110-6116.

3. Brandli RC, Hartnik T, Henriksen T, Cornelissen G (2008) Sorption of native polyaromatic hydrocarbons (PAH) to black carbon and amended activated carbon in soil. Chemosphere 73: 1805-1810.

4. Wu Y, Xia L, Yu Z, Shabbir S, Kerr PG (2014) In situ bioremediation of surface waters by periphytons. Bioresour Technol 151: 367-72.

5. Boopathy R (2000) Factors limiting bioremediation technologies. Bioresource Technol 74: 63-67.

6. Sivakumar G, Xu J, Thompson RW, Yang Y, Randol-Smith P (2012) Integrated green algal technology for bioremediation and biofuel. Bioresour Technol 107: $1-9$

7. Srinivasan A, Viraraghavan T (2010) Decolorization of dye wastewaters by biosorbents: a review. J Environ Manage 91: 1915-1929.

8. Romera E, Gonzalez F, Ballester A, Blazquez ML, Munoz JA (2006)B Biosorption with algae: a statistical review. Critical reviews in biotechnology 26: 223-35.

9. Perales-Vela HV,Pena-Castro JM, Canizares-Villanueva R O (2006) Heavy metal detoxification in eukaryotic microalgae. Chemosphere 64: 1-10.

10. Treguer PJ, De La Rocha CL (2013) The world ocean silica cycle. Annual review of marine science 5: 477-501.

11. Gorman DS, Levine R P (1965) Cytochrome f and plastocyanin: their sequence in the photosynthetic electron transport chain of Chlamydomonas reinhardi Proceedings of the National Academy of Sciences of the United States of America 54: 1665-9.

12. Association APH, APHA (2005) Method 3500-CU: Standard Methods for the Examination of Water and Wastewater. In 40 CFR 444.12. American Public Health Association: Washington DC

13. Descles J, Vartanian M, El Harrak A, Quinet M, Bremond N et al. (2008) New tools for labeling silica in living diatoms. The New phytologist 177: 822-9.

14. Vanblaaderen A, Vrij A (1993) Synthesis and Characterization of Monodisperse Colloidal Organo-Silica Spheres. J Colloid Interf Sci 156: 1-18.

15. Kroger N, Lorenz S, Brunner E, Sumper M (2002) Self-assembly of highly phosphorylated silaffins and their function in biosilica morphogenesis. Science 298: 584-6.

16. Hanikenne $M(2003)$ Chlamydomonas reinhardtii as a eukaryotic photosynthetic model for studies of heavy metal homeostasis and tolerance. New Phytologis 159: $331-340$

17. Miller D, Lampor DT, Miller M (1972) Hydroxyproline heterooligosaccharides in Chlamydomonas. Science 176: 918-20.

18. Bayramoglu G, Tuzun I, Celik, G, Yilmaz M, Arica MY (2006) Biosorption of mercury(II), cadmium(II) and lead(II) ions from aqueous system by microalgae Chlamydomonas reinhardtii immobilized in alginate beads. Int J Miner Process 81: $35-43$

19. Tuzun I, Bayramoglu G, Yalcin E, Basaran G, Celik, G et al. (2005) Equilibrium and kinetic studies on biosorption of $\mathrm{Hg}(\mathrm{II}), \mathrm{Cd}(\mathrm{II})$ and $\mathrm{Pb}$ (II) ions onto microalgae Chlamydomonas reinhardtii. J Environ Manage 77: 85-92.

20. Hill KL Hassett R, Kosman D, Merchant S (1996) Regulated copper uptake in Chlamydomonas reinhardtii in response to copper availability. Plant Physiol 112: 697-704.

21. Boswell C, Sharma NC, Sahi SV (2002) Copper tolerance and accumulation potential of Chlamydomonas reinhardtii. B Environ Contam Tox 69: 546-553.

22. Danilov RA, Ekelund NG (2001) Effects of $\mathrm{Cu}^{2+}, \mathrm{Ni}^{2+}, \mathrm{Pb}^{2+}, \mathrm{Zn}^{2+}$ and 
Citation: Li X, Gui S, Bhuiyan M, Zeng W, Subedi Y, et al. (2015) Quantifying Uptake and Retention of Copper lons in Silica-Encrusted Chlamydomonas reinhardtii. Biochem Anal Biochem 4: 228. doi:10.4172/2161-1009.1000228

pentachlorophenol on photosynthesis and motility in Chlamydomonas reinhardtii in short-term exposure experiments. BMC ecology 1: 1

23. Nakajima A, Horikoshi T Sakaguchi T (1979) Studies on the Accumulation of Heavy-Metal Elements in Biological-Systems. Agr Biol Chem Tokyo 43: 14551460.

24. Patwardhan SV, Clarson SJ (2003) Silicification and biosilicification: Part 5 - An investigation of the silica structures formed at weakly acidic $\mathrm{pH}$ and neutral $\mathrm{pH}$ as facilitated by cationically charged macromolecules. Mat Sci Eng C-Bio S 23: 495-499.

25. Schönknecht G, Chen WH, Ternes CM, Barbier GG, Shrestha RP (2013) Weber AP "Gene transfer from bacteria and archaea facilitated evolution of an extremophilic eukaryote" Science 339: 1207-1210.

26. US Environmental Protection Agency (1992). 


\section{Supplemental figures:}

Figure S1: Growth Curve of Chlamydomonas reinhardtii at Different Copper (II) Concentration: 0 (black), 3.8 (blue), 7.6 (red), 14.2 (green), 28.4 (purple), and 56.9 (orange) ppm.

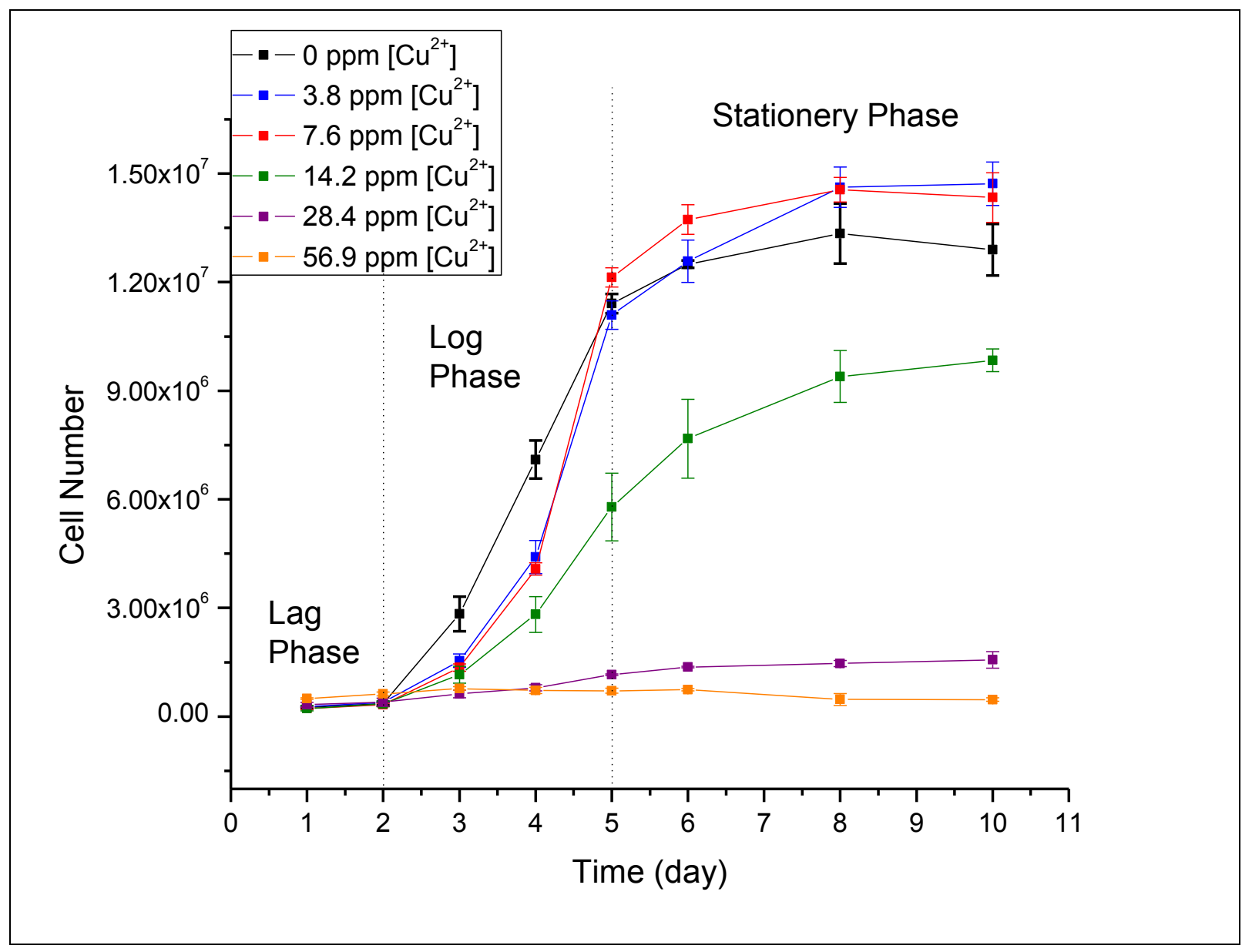

